\title{
Academic Performance and Cognitive Load in Mobile Learning
}

https://doi.org/10.3991/ijim.v14i21.18439

\author{
Korlan Zhampeissova $(\bowtie)$ \\ Abai Kazakh National Pedagogical University, Almaty, Kazakhstan \\ zhampeissova44@rambler.ru / khorlan_17@mail.ru \\ Alena Gura \\ Kuban State Technological University, Krasnodar, Russia \\ Ekaterina Vanina, Zhanna Egorova \\ I.M. Sechenov First Moscow State Medical University, Moscow, Russia
}

\begin{abstract}
The study considers the influence of cognitive load on the achievement of educational goals in the context of mobile learning. It has been proved that the effectiveness of educational programs in a mobile learning environment is achieved by harmonizing cognitive load and structuring the educational content. The experiment was performed in order to identify pedagogical tools to ensure the effective use of the mental resources of students and to reduce their cognitive load when studying educational materials. The experiment was performed within the educational programs of Sechenov First Moscow State University (Russia) and Abai Kazakh National Pedagogical University (Kazakhstan). Traditional classroom learning was supplemented with electronic educational resources and a mobile learning program developed on the basis of iSpring Cloud Storage mobile learning platform with a focus on the study of national values and education. The experimental groups were offered three different approaches to studying a discipline in a digital environment based on mobile learning. The observation of the learning process helped the authors to identify the key aspects of effective educational practice in a mobile learning environment. These include high-quality educational content; thematic and temporal structuring of the educational process; distribution of cognitive load in the educational course; introduction of tools to encourage student attention; active participation of students in the educational process; synergy of knowledge accumulation and delivery in the learning environment; thematic social interaction of educational group members. The results of the experiment confirmed the constructive influence of pedagogical tools aimed at the reduction of students' cognitive load on the effectiveness of educational programs in a mobile learning strategy.
\end{abstract}

Keywords - Cognitivism, mobile learning, educational design, extraneous cognitive load (ECL), germane cognitive load (GCL), intrinsic cognitive load (ICL), learning efficiency 


\section{Introduction}

The age of accelerated technological progress is characterized by innovations, high availability of information, easy access to digital resources and the constant presence of mobile technologies in daily life [1]. Mobile computing has become incredibly popular due to the use of the Internet, e-mail, multimedia technologies and intelligent learning systems [2]. Generations of students born in this era are accustomed to having access to instant and multiple sources of information, multitasking and social connection with peers via mobile technologies. The conglomerate of new mobile technologies and the digital development of social and cognitive skills of the modern generation requires new solutions in education [3].

The use of digital technologies not only increases the number of opportunities, but limits them as well [4-6]. The cognitive load on students increases several times due to the constant flow of information present in the digital environment and thus relevant study and training are required. The use of mobile technology as a learning substrate can increase cognitive load or reduce it $[7,8]$. The presented research is devoted to the solution of this problem.

Expansion of online technologies and totalization of mobile applications in all spheres of life have greatly affected the concept of educational design. The integration of mobile applications with $\mathrm{Wi}-\mathrm{Fi}, 4 \mathrm{G}$ and $5 \mathrm{G}$ networks allows students to access educational material, including lectures, assignments, and quizzes, as well as to collaborate and receive support regardless of their location and time [9]. Portable mobile devices are extremely important tools that ensure learning that combines authentic learning aspects with usage of digital environment. A mobile learning makes it possible to master knowledge based on one's life experience and provides one with digital support in the right place at the right time [4]. Mobile devices allow acquiring and sharing knowledge regardless of space or time [10]. User-friendliness and flexibility are the key advantages of mobile learning [11]. Multimedia-based learning not only improves cognition, reduces learning anxiety, and increases motivation to study, but also provides relevant visual and auditory support [1].

A variety of different features of mobile devices such as individual interfaces, realtime information access, context sensitivity, and instant feedback are considered. Part of the mentioned features can reinforce pedagogical practices which rely on mobile technologies that have become intermediaries in the learning process providing new methods of accessing and using learning opportunities and defining models of digital, in particular, mobile learning [12]. However, there is a need for more functions to be introduced to achieve more positive learning effect. In practice, the "key" to the integration of mobile devices with educational strategies should be found and special capabilities of mobile technologies should be used to solve specific pedagogical problems [13].

Mobile learning provides great opportunities to improve learning experience by offering flexibility and personalization. Nevertheless, a technological solution itself cannot meet the needs of modern consumers of educational services, whose priorities are efficiency, quality and conciseness of the educational process. In this regard, modern 
scientific research is aimed at identifying factors affecting the improvement of education in the mobile format, which is focused on the cognitive aspects of educational practices rather than the technological capabilities of mobile learning platforms.

Thus, the purpose of the study is to investigate the impact of the cognitive load of students on the achievement of educational goals in the context of mobile learning. The following research objectives have been set:

- Developing three approaches to studying a discipline based on the I Spring Cloud Storage platform.

- Designing an educational process in the mobile learning environment with a focus on reducing the cognitive load of students.

- Introducing an experimental educational practice and studying the influence of technological and structural aspects of the educational process on the effectiveness of education.

- Identifying the correlation between the cognitive load of students in the process of studying a discipline and the effectiveness and efficiency of the learning process.

\section{$1.1 \quad$ Research structure}

The introduction presents the background of the research, the main problems and goals of the research. Theoretical in sigh review focuses on the previous works on the topic and the uniqueness of the present study among them. The research design section describes in detail research methods. The results and discussion describe the findings of the study and compare them with similar results in other studies.

\subsection{Theoretical insights}

Learning is a "constructive process of conceptual growth" that requires increased cognitive activity [5].

The cognitive load theory was introduced in the 1980s; it demonstrated the interaction between human cognitive structure and cognitive objects in process of learning or through performance of tasks. Cognitive architecture consists of short-term and longterm memory, in which conscious cognitive processing takes place [6]. Only a small number of new integrable elements can be used by human memory at the same time, perhaps no more than five. In this regard, inadequately designed educational content and strategies can exceed the cognitive load due to the overload of students' working memory [14].

The resources of consciousness necessary to complete the task should be divided into several separate categories: intrinsic, extraneous, and germane cognitive load [7,15] (Fig. 1). 


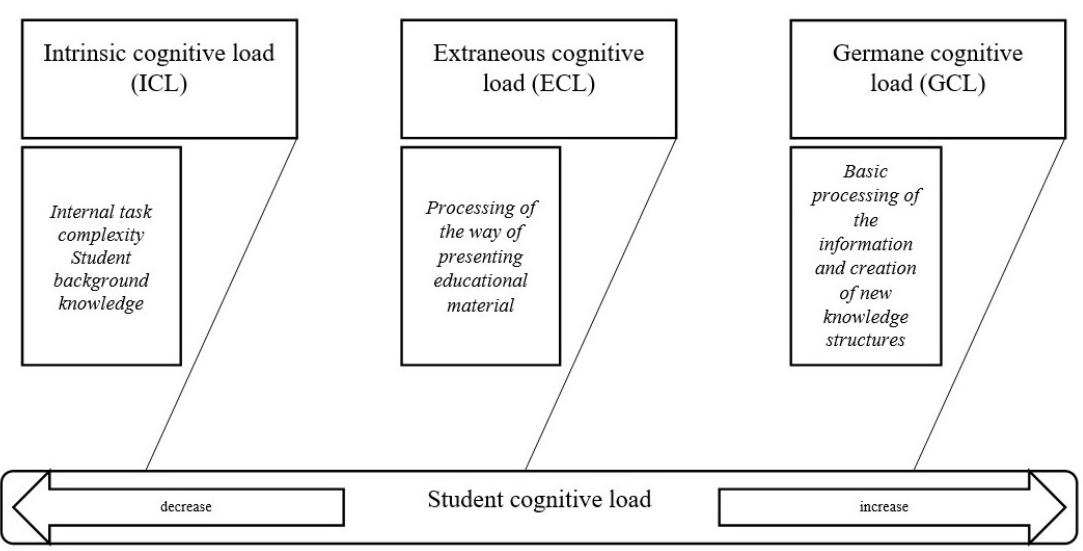

Fig. 1. Cognitive load structure

* Authors' development based on [14]

Intrinsic Cognitive Load (ICL) refers to the efforts of consciousness to overcome the difficulties of understanding the internal structure of the task and finding a solution. ICL depends on student background knowledge. Background knowledge allows a student to apply their own educational tactics to master new information, which reduces cognitive load. Amount of information the working memory has to process refers to intrinsic cognitive load; it increases when an interactivity element is added. The usefulness of interactivity depends on the amount of diverse data types that students should integrate and assimilate simultaneously [14].

Extraneous Cognitive Load (ECL) relates to efforts of consciousness to understand the way teaching material is presented. An increase in the extraneous cognitive load of a student is associated with poor educational strategies that do not consider important learning variables [14].

Germane Cognitive Load (GCL) is associated with the basic processing of the information and the creation of new knowledge structures. GCL distributes ICL and ECL; therefore, it is not independent. However, GCL is an indicator of some learning processes.

Cognitive loading is manifested in the modern digital environment not only in early school education, but even in preschool one, which requires the use of special pedagogical technologies for the normal development of students' cognitive abilities $[8,16]$. One of the most pressing problems in studying the phenomenon of cognitive loading is the lack of effective and objective methods for measuring it, which is why most studies are forced to rely on subjective assessment or the results of measuring the knowledge gained by students through tests $[4,10]$.

Cognitive load is a consequence of the learning path and the key factor determining learning outcomes [4]. It is critically dependent on the chosen method of presenting information, the level of student motivation, their involvement and the lack of academic concern. Using the digital environment familiar to recent generations, in particular, the introduction of mobile learning, can improve the distribution of cognitive load $[17,18]$. 
The cognitive load is a significant indicator that demonstrates the impact of modern learning technologies and digital environment on conceptual learning and students' cognitive development [19].

\section{$2 \quad$ Research Design}

The experiment was performed within the course of national education disciplines. Traditional classroom learning was supplemented with electronic educational resources and a mobile learning program with a focus on the study of national values and education.

Due to the fact that the study of disciplines required a student to memorize a large amount of information, a mobile educational product with structured educational content was developed. The experiment was performed in order to identify pedagogical tools to ensure the effective use of the mental resources of students and to reduce their cognitive load when studying educational materials.

The research was carried out in 2019-2020 as part of the educational programs of Sechenov First Moscow State University (Russia) and Abai Kazakh National Pedagogical University (Kazakhstan). Three experimental groups were trained simultaneously: group 1 - in Kazakhstan, groups 2 and 3 - in Russia. The content of the training programs was identical in volume as well as in the structure and sequence of presentation of the material. Thus, the experiment was also limited to the study of teaching methods and technologies.

The study involved 111 first-year students studying "Clinical psychology", "Preschool education and upbringing", "Pedagogy and methods of primary education", "Pedagogy and psychology", "Defectology", "Social pedagogy and self-knowledge" (Table 1).

Table 1. Research sampling

\begin{tabular}{|c|c|c|c|c|c|}
\hline University & Institution & Program of study & \begin{tabular}{|c|}
$\begin{array}{c}\text { Number } \\
\text { of } \\
\text { students }\end{array}$ \\
\end{tabular} & Age & Gender \\
\hline $\begin{array}{l}\text { Sechenov First Mos- } \\
\text { cow State University } \\
\text { (Russia) }\end{array}$ & $\begin{array}{l}\text { Institute of Linguis- } \\
\text { tics and Intercultural } \\
\text { Communication }\end{array}$ & Clinical psychology & 30 & $18-23$ & $\begin{array}{l}\text { Male }-10 \\
\text { Female }-20\end{array}$ \\
\hline \multirow{5}{*}{$\begin{array}{l}\text { Abai Kazakh } \\
\text { National Pedagogical } \\
\text { University } \\
\text { (Kazakhstan) }\end{array}$} & \multirow{5}{*}{$\begin{array}{l}\text { Institute of Pedagogy } \\
\text { and Psychology }\end{array}$} & $\begin{array}{l}\text { Preschool education and } \\
\text { upbringing }\end{array}$ & 22 & 20 & $\begin{array}{l}\text { Male }-0, \\
\text { Female - } 22\end{array}$ \\
\hline & & $\begin{array}{l}\text { Pedagogy and methods of } \\
\text { primary education }\end{array}$ & 25 & 22 & $\begin{array}{l}\text { Male }-0, \\
\text { Female }-25\end{array}$ \\
\hline & & Pedagogy and psychology & 8 & 20 & $\begin{array}{l}\text { Male }-0, \\
\text { Female }-8\end{array}$ \\
\hline & & Defectology & 17 & 20 & $\begin{array}{l}\text { Male }-0, \\
\text { Female }-17\end{array}$ \\
\hline & & $\begin{array}{l}\text { Social pedagogy and self- } \\
\text { knowledge }\end{array}$ & 9 & 20 & $\begin{array}{l}\text { Male }-5, \\
\text { Female }-4\end{array}$ \\
\hline
\end{tabular}


The experimental group was divided into 3 subgroups that were offered 3 different approaches to studying a discipline in the mobile format (Fig. 2).

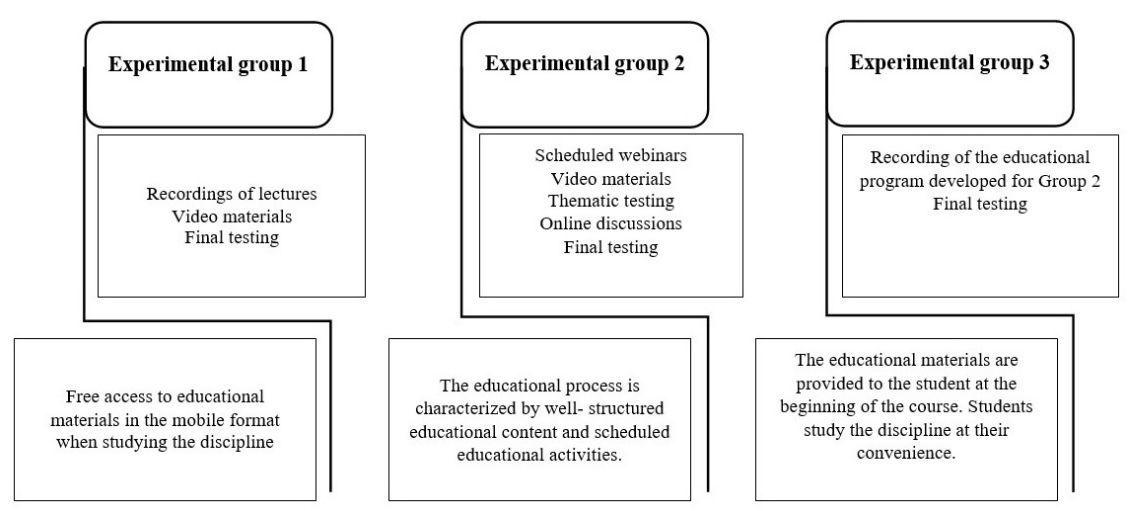

Fig. 2. Approaches to studying a discipline

*Authors' development

\subsection{Ethical issues}

All study participants were recruited on a voluntary basis and on condition of maintaining anonymity. Their personal data were not collected or stored during or after the study. The final test for statistical processing was carried out using unique identifiers assigned to each of the participants, which made the study anonymous.

Experimental group 1 (37 students) studied a discipline in the distance learning format based on the following structure: recording of lectures + video materials + questions' review.

The educational process for experimental group 2 (37 students) was characterized by well-structured educational content and scheduled educational activities. The following mobile learning tools were used in the experiment: I Spring Cloud Storage (a platform for sharing mobile learning resources) and Mirapolis Virtual Room (a platform for participation in webinars). The educational process was based on the following scheme (Fig. 3): 


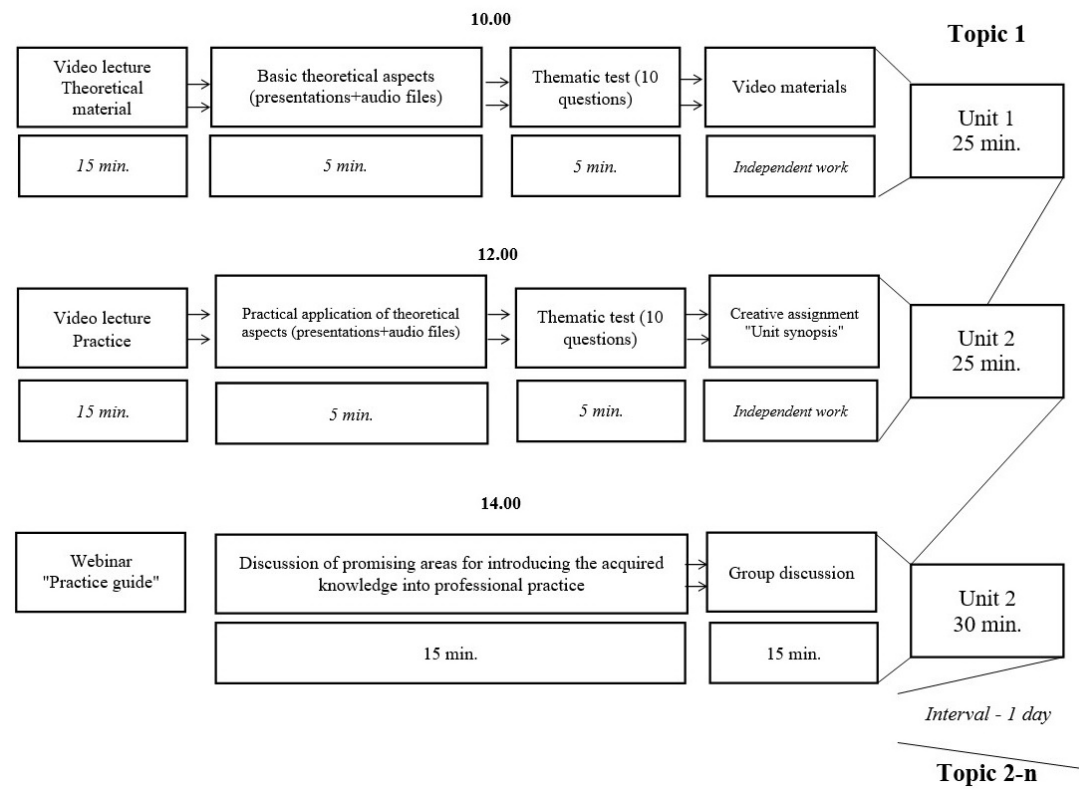

Fig. 3. Educational process in the mobile learning environment

*Authors' development

At the beginning of the course, experimental group 3 (37 students) was provided with the recording of the educational program that did not require students to schedule their educational activities and participate in discussions. Students studied a discipline at their convenience; the emphasis was placed on self-organization. After the completion of the course, the participants took a final test. The final test consisted of 20 questions in the studied discipline with a choice of answers out of 5 possible. One of the answers was completely incorrect and was worth 0 points for the final grade; other answers contained some part of the correct answer and brought 2 - 4 points, one of the answers was completely correct and brought 5 points. The maximum possible score was 100 points.

Statistical studies of test results were carried out and the data were visualized using the MS Excel 2013 program.

\section{Results and Discussion}

Final assessment showed the difference in the level of knowledge of the participants in the experimental groups (see Fig. 4). 


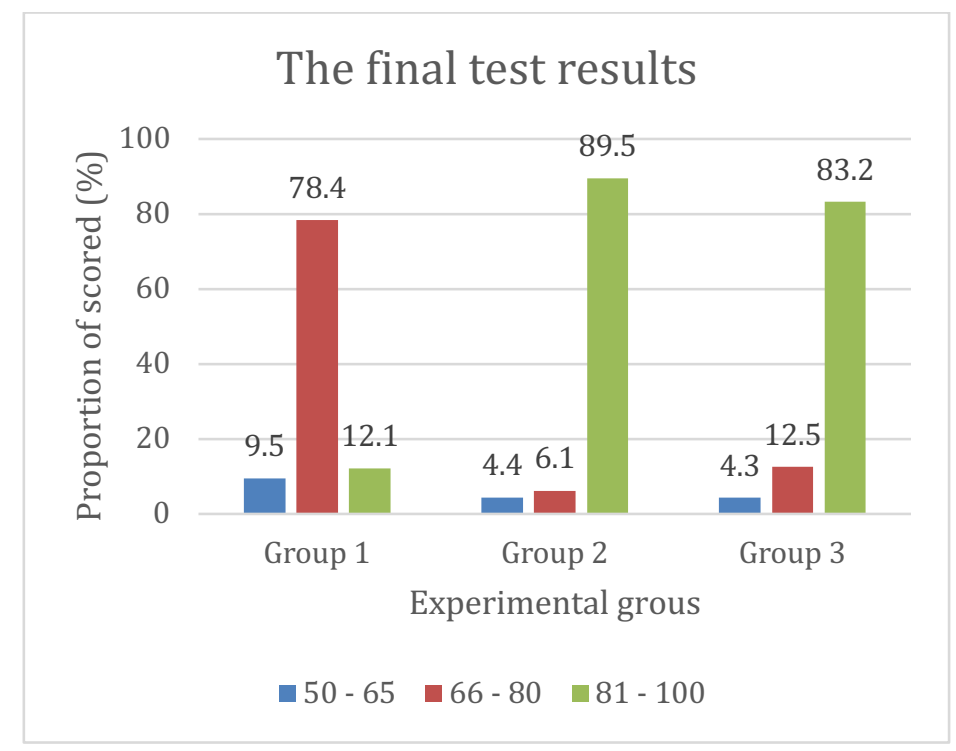

Fig. 4. The final test results

None of the groups had scores below 50 points in total.

Experimental group 1, which had free access to educational materials in the mobile format, demonstrated a low level of knowledge; this was associated with the unstructured learning process. Most of the group members confirmed that the study of educational materials was fragmentary and not all provided educational resources were used. The knowledge of $78 \%$ of students, according to the results of the final testing, was assessed in the range of $60-75$ points. The majority of students found the course to be boring and the amount of educational information to be too large; this became the main learning obstacle.

Experimental group 2 produced an excellent result - about $90 \%$ of the participants successfully passed the final test (85-98).

When studying the learning experience of experimental group 2 and analyzing the participants' feedback, it can be concluded that good results were achieved due to:

- Convenient mobile learning format.

- Thematic and temporal structuring of the educational process.

- Effective distribution of cognitive load in units that were not longer than 30 minutes; this made it possible to maximize the use of mental resources and easily memorize a large amount of educational information.

- Thematic testing at the end of the video lesson, which encouraged students to watch and listen to the educational material.

- Creative tasks, which perfectly solidified the acquired knowledge.

- Thematic discussions, which revealed promising areas for introducing the acquired knowledge into professional practice; this encouraged the involvement and interest of students in the study of educational materials. 
Experimental group 3, which was provided with the recording of the mobile learning program at the beginning of the course, also showed good results. The knowledge of $83 \%$ of students was assessed in the range from 77 to 87 points. Most of the participants confirmed that the achievement of positive results was associated with a free and comfortable format of learning, as well as a high-quality and structured educational resource. Due to the fact that the study of a discipline had no time frame and was focused on self-regulated learning, most of the students confirmed that they had difficulties with self-organization and postponed learning. Fifty-six percent of all participants demonstrated poor motivation for memorizing educational materials; this was associated with the availability of the educational program in their mobile phones that they equated with the possession of knowledge. Thus, this became a demotivating factor.

Based on the observation of the learning process and taking into account the difference in the results demonstrated by groups with different teaching methods and technologies (Fig. 4), the key aspects of effective educational practice in a mobile learning environment should be identified, namely:

- High-quality educational content (more effective in groups 2 and 3).

- Thematic and temporal structuring of the educational process (scheduled and wellconstructed educational context in groups 2 and 3).

- Distribution of cognitive load in the educational course (in group 2 optimal).

- Introduction of tools to encourage student attention (in groups 2 and 3).

- Active participation of students in the educational process (in groups 2 and 3).

- Synergy of knowledge accumulation and delivery in the learning environment (in all groups).

- Thematic social interaction of the members of the educational group (in all groups).

The cognitive perception of learning focuses on the argument that knowledge acquisition is the foundation of learning. It is expected that any new data obtained by an individual will be used in various circumstances. The application of knowledge depends on the way it is understood and stored in the long-term memory of an individual [17]. The cognitive approach places a student and internal mental processes at the center of learning. Due to the fact that cognitivism seeks to identify various processes associated with the acquisition of knowledge and thus to provide strategies that support student learning, educators can use cognitive approaches to help students effectively achieve their educational goals [20].

The results of this study show the dependence of the academic results (objectively assessed using the test) on the level of cognitive load of students and the mobile technologies used for teaching. Thus, the authors are trying to establish certain relationships between the use of mobile learning technologies and a decrease in cognitive load, which should not lead to deterioration in results (see the differences in the results of groups 2 and 3).

Learning scenarios supported by mobile technologies can be too complex and insufficiently effective without proper teacher guidance [21]. Many studies have shown that familiarity and daily use of mobile devices do not make them a learning tool without additional training and instruction. The best method for developing mobile learning skills is training from the preschool period, at the time of the formation of cognitive 
abilities in a natural digital environment $[16,18]$. In order for such a formation to be as easy as possible and to give a result in the form of academic achievements in adulthood, the level of acceptance, assimilation and professionalism in the use of mobile technologies by teachers is of importance [22,23].

Students may feel embarrassed and frustrated when faced with both real educational goals and digital resources to achieve them. Thus, appropriate educational activities and effective strategies to guide students in digital resources use should be developed [24]. Cognitive load can be reduced even in a technologically advanced environment when the educational system and activities are properly designed [4].

Authenticity is the key aspect of mobile learning as it allows students to meaningfully learn in real-life scenarios. Thus, there is a need for effective strategies to enable students to learn in context-sensitive mobile learning scenarios that combine educational resources from the digital world. The introduction of game-based learning can significantly improve student motivation due to the multi-stage mechanism for managing the individual educational process [25]. The combination of real and virtual learning components in accordance with the principles of the spatial and temporal architecture of educational courses promotes effective learning and reduces student cognitive load [26]. In the present study, the best results were demonstrated by groups that had a wider and more diverse digital presentation of materials as well as gamification of learning that increased motivation for the process.

Augmented reality mobile apps help create an effective learning environment and leverage new pedagogical opportunities. Virtual objects carrying teaching functions are integrated into the real world of a student. This technique makes it possible to interact with the environment in new ways using mobile devices. Mobile learning ensures easy and comfortable learning that requires minimal cognitive effort. The limited cognitive efforts of students with a large volume of educational material were also confirmed by the current research. Sensory experience and real-time interaction with the environment can provide learning satisfaction and allow students to structure knowledge to accomplish their learning objectives [27].

It is no coincidence that the central challenge of this study is to overcome the increased cognitive load on students in the process of mobile learning [4,9]. Cognitive load has been increasing due to the development of science, digital environment, and the impact of a continuous flow of information [10].

The mobile learning programs' effect should be strengthened through longer learning intervals, closer integration of curriculum with technical devices, and further assessment of more advanced skills. This is especially relevant for preschool, early school and high school education [28]. The length of a training course affects the reliability and sustainability of mobile learning programs. Short-term educational programs, especially those that involve a few learning hours, do not allow identifying whether the effects were created by the features of integrated mobile learning or by technological innovation [13].

Assessment in a mobile learning environment includes a number of different aspects, such as learning efficiency, interactivity, user-friendly interface and education quality. Distance learning complicates the assessment process and forces educational institutions to consider the technical aspects of mobile learning, social norms, and pedagogical 
theories, including learning strategies, learning outcomes, engagement, and collaboration. Therefore, the development and implementation of mobile learning technologies should be integrated with traditional education aspects to ensure the sustainability of the learning system on mobile basis [20].

The introduction of new technological solutions into the learning environment requires increased attention to the sphere of mutual influence of culture and rapidly changing technology. Technological tools should be properly used given their possible impact on the transformation of cultural practices. The need to take into account the peculiarities of culture makes the development of training interfaces more difficult and requires the inclusion of many additional parameters. Basically, it is important to understand the nature of the target student culture and use the data as a basis for the development of educational programs in a mobile learning environment [20].

\section{Conclusion}

The study considers the influence of cognitive load on the achievement of educational goals in the context of education through mobile technologies. It has been proven that the effectiveness of educational programs in a mobile learning environment is achieved by harmonizing cognitive load and structuring the educational content.

The experiment was performed in order to identify pedagogical tools to ensure the effective use of the mental resources of students and to reduce their cognitive load when studying educational materials. The experiment was performed within the educational programs of Sechenov First Moscow State University (Russia) and Abai Kazakh National Pedagogical University (Kazakhstan). Traditional classroom learning was supplemented with electronic educational resources and a mobile learning program developed on the basis of the I Spring Cloud Storage mobile learning platform with a focus on the study of national values and education. The experimental group was divided into 3 subgroups that were offered 3 different approaches to studying a discipline in the mobile format.

Based on the observation of the learning process the key aspects of effective educational practice in a mobile learning environment have been identified. These include high-quality educational content; thematic and temporal structuring of the educational process; distribution of cognitive load in the educational course; introduction of tools to encourage student attention; active participation of students in the educational process; synergy of knowledge accumulation and delivery in the learning environment; thematic social interaction of educational group members.

It was found that a significant cognitive load leads to a noticeable deterioration in the results of students without the use of special educational technologies. In addition, the results of the experiment confirmed the constructive influence of pedagogical tools (aimed at the reduction of cognitive load of students) on the effectiveness of educational programs in a mobile learning strategy. Future research can focus on specific aspects of the cognitive load impact of mobile learning on students of various specialties in order to enhance their academic achievement. 


\subsection{Research limitations}

The development of the educational process design in the mobile learning format was aimed at identifying pedagogical tools for reducing the cognitive load of students when studying the discipline, which facilitated memorizing of the educational material. Due to the fact that cognitive load contributes to the development of new knowledge structures, the research should not be reduced to studying the tools for its reduction, but focus on cognitive management.

\section{$5 \quad$ References}

[1] Perminov, E.A., Gadjiev, D.D., Abdurazakov, M.M. (2019). About relevance of fund mentalization of mathematical training of students of the pedagogical directions during the digital era. The Education and science journal, 21(5):86-111. (In Russian). https://doi.org/10.17853/1994-5639-2019-5-87-112

[2] Talib, C.A., Aliyu, H, Malik, A.M, Siang, K.H., Novopashenny, I., Ali, M. (2019). Sakai: A Mobile Learning Platform. International Journal of Interactive Mobile Technologies, 13(11): 95-110. https://doi.org/10.3991/ijim.v13i11.10800

[3] Fomina, S., Sizikova, V., Shimanovskaya, Y., Kozlovskaya, S., Karpunina, A. (2019). The effect of teaching and supply chain management on employees' skills in small and medium sized enterprises of Russia. International Journal of Supply Chain Management, 8(4): 930938.

[4] Curum, B., Khedo, K.K. (2020). Cognitive load management in mobile learning systems: principles and theories. Journal of Computers in Education, 1: 1-28. https://doi.org/10.1007 /s40692-020-00173-6

[5] Winne, P. H. (2018). Cognition and metacognition within self-regulated learning. In D.H. Schunk, J.A. Greene (Eds.), Educational psychology handbook series. Handbook of selfregulation of learning and performance. Routledge/Taylor \& Francis Group, pp. 36-48. https://doi.org/10.4324/9781315697048-3

[6] Sweller, J. (2016). Cognitive load theory, evolutionary educational psychology, and instructional design. In Evolutionary perspectives on child development and education. Springer, Cham, pp. 291-306. https://doi.org/10.1007/978-3-319-29986-0_12

[7] Leppink, J., Paas, F., van Gog, T., van der Vleuten, C., van Merrienboer, J. (2014). Effects of pairs of problems and examples on task performance and different types of cognitive load. Learning and Instruction, 30: 32-42. https://doi.org/10.1016/j.learninstruc.2013.12.001

[8] Papadakis, S., Kalogiannakis, M. (2017). Mobile educational applications for children: what educators and parents need to know. International Journal of Mobile Learning and Organization, 11(3): 256-277. https://doi.org/10.1504/ijmlo.2017.085338

[9] El-Sofany, H., El-Haggar, N. (2020). The Effectiveness of Using Mobile Learning Techniques to Improve Learning Outcomes in Higher Education. International Journal of Interactive Mobile Technologies, 14(8): 4-18. https://doi.org/10.3991/ijim.v14i08.13125

[10] Tal, I., Ibarrola, E., Muntean, G.M. (2016). Quality and standardization in technology-enhanced learning. In 2016 ITU Kaleidoscope: ICTs for a Sustainable World (ITU WT). IEEE, pp. 1-8. https://doi.org/10.1109/itu-wt.2016.7805715

[11] Hanafi, Y., Murtadho, N., Ikhsan, M.A., Diyana, T.N. (2020). Reinforcing Public University Student's Worship Education by Developing and Implementing Mobile-Learning Management System in the ADDIE Instructional Design Model. International Journal of Interactive Mobile Technologies, 14(2): 215-241. https://doi.org/10.3991/ijim.v14i02.11380 
[12] Blilat, A., Ibriz, A. (2020). Design and Implementation of P2P Based Mobile App for Collaborative Learning in Higher Education. International Journal of Interactive Mobile Technologies, 14(7): 115-132. https://doi.org/10.3991/ijim.v14i07.13167

[13] Sung, Y.T., Chang, K.E., Liu, T.C. (2016). The effects of integrating mobile devices with teaching and learning on students' learning performance: A meta-analysis and research synthesis. Computers \& Education, 94: 252-275. https://doi.org/10.1016/j.compedu. 2015.11.008

[14] Alyushin, M.V., Kolobashkina, L.V. (2019). Monitoring of the current status of students as a means of increasing the effectiveness of educational process. The Education and science journal, 21(2): 176-197. (In Russian). https://doi.org/10.17853/1994-5639-2019-2-176-197

[15] Sweller, J., Van Merrienboer, J.J., Paas, F. (2019). Cognitive architecture and instructional design: 20 years later. Educational Psychology Review, 32(2): 261-262. https://doi.org/10.1007/s10648-019-09465-5

[16] Dorouka, P., Papadakis, S., Kalogiannakis, M. (2020). Tablets and apps for promoting robotics, mathematics, STEM education and literacy in early childhood education. International Journal of Mobile Learning and Organization, 14(2): 255-274. https://doi.org/10.1504 iijmlo.2020.10026334

[17] Afzal, A., Babar, S. (2016). Making lectures memorable: A cognitive perspective. Journal of Pakistan Medical Association, 66(8): 1024.

[18] Papadakis, S., Vaiopoulou, J., Kalogiannakis, M., Stamovlasis, D. (2020). Developing and Exploring an Evaluation Tool for Educational Apps (ETEA) Targeting Kindergarten Children. Sustainability, 12(10): 4201. https://doi.org/10.3390/su12104201

[19] Evplova, E.V. (2019). Social characteristics of personal and corporate competitiveness of future specialists: results of sociological research. The Education and science journal, 21(2): 132-154. (In Russian). https://doi.org/10.17853/1994-5639-2019-2-132-154

[20] Al-Hunaiyyan, A., Bimba, A.T., Idris, N., Al-Sharhan, S. (2017). A cognitive knowledgebased framework for social and metacognitive support in mobile learning. Interdisciplinary Journal of Information, Knowledge, and Management, 12: 75-98. https://doi.org/10. $28945 / 3670$

[21] Thongkoo, K., Panjaburee, P., Daungcharone, K. (2019). A development of ubiquitous learning support system based on an enhanced inquiry-based learning approach. International Journal of Mobile Learning and Organization, 13(2): 129-151. https://doi.org/ 10.1504/ijmlo.2019.10017842

[22] Papadakis, S. (2018). Evaluating pre-service teachers' acceptance of mobile devices with regards to their age and gender: a case study in Greece. International Journal of Mobile Learning and Organization, 12(4): 336-352. https://doi.org/10.1504/ijmlo.2018.10013372

[23] Kalogiannakis, M., Papadakis, S. (2019). Evaluating pre-service kindergarten teachers' intention to adopt and use tablets into teaching practice for natural sciences. International Journal of Mobile Learning and Organization, 13(1): 113-127. https://doi.org/10.1504/ijmlo.2 019.10016617

[24] Chen, C.C., Chen, C.Y. (2018). Exploring the effect of learning styles on learning achievement in a u-Museum. Interactive Learning Environments, 26(5): 664-681. https://doi.org/ $\underline{10.1080 / 10494820.2017 .1385488}$

[25] Chen, C.H., Liu, G.Z., Hwang, G.J. (2016). Interaction between gaming and multistage guiding strategies on students' field trip mobile learning performance and motivation. British Journal of Educational Technology, 47(6): 1032-1050. https://doi.org/10.1111/bjet.12270

[26] Thees, M., Kapp, S., Strzys, M.P., Beil, F., Lewkowicz, P., Kuhn, J. (2020). Effects of augmented reality on learning and cognitive load in university physics laboratory courses. Computers in Human Behavior, 108: 106316. https://doi.org/10.1016/j.chb.2020.106316 
[27] Küçük, S., Kapakin, S., Göktaş, Y. (2016). Learning anatomy via mobile augmented reality: Effects on achievement and cognitive load. Anatomical sciences education, 9(5): 411-421. https://doi.org/10.1002/ase.1603

[28] Papadakis, S., Kalogiannakis, M., Zaranis, N. (2017). Designing and creating an educational app rubric for preschool teachers. Education and Information Technologies, 22(6): 3147 3165. https://doi.org/10.1007/s10639-017-9579-0

\section{Authors}

Zhampeissova Korlan Kabykenovna is a Doctor of Pedagogical Sciences, Professor of the Department of Pedagogy, Abai Kazakh National Pedagogical University, Almaty, Kazakhstan. Email: zhampeissova44@rambler.ru, khorlan17@mail.ru

Gura Alena Yurevna is a PhD in philosophy, Associate Professor of the Department of History, Philosophy and Psychology, Kuban State Technological University, Krasnodar, Russia.

Vanina Ekaterina Sergeevna is a Lecturer of the Department of Physical Education, I.M. Sechenov First Moscow State Medical University, Moscow, Russia.

Egorova Zhanna Borisovna is a Lecturer of the Department of Physical Education, I.M. Sechenov First Moscow State Medical University, Moscow, Russia.

Article submitted 2020-09-11. Resubmitted 2020-10-18. Final acceptance 2020-10-19. Final version published as submitted by the authors. 